\title{
THE FLARE ACTIVITY OF TWO IWIERESTING RED DWARFS
}

\author{
I. V.I Iyin, N.I. Shakhovskaya \\ Crimean Astrophysical Observatory \\ Crimea Nauchny, IS4A1S USSFi
}

\begin{abstract}
Fhotoelectric observations of flares on two low-active red dwarfs (Gliese $171.2 A$ and CM Dra) are reported.
\end{abstract}

The analysis of many years of photographic observations of Gliese 171. 2A has shown the largest amplitude long-terin cyclic variation of brightness, which is attributable, as for EY Dra spotted stars, to solar-like cool surface structures (Hartmann et al., 1901). No flare activity of this star had been ever observed. Therefore, we carried out photoelectric observations of Gliege $171.2 A$ in $U$ band on 4 and 5 December 1983 at the $1.25 \mathrm{~m}$ telescope of Crimean Astrophysical observatory using a one-channel photon-counting photometer. During the course of the first night, five flares were observed, while during the second night the star was quite inactive. The photoelectric recordings are shown in figure 1 . The cause of the light decrease close to $19 \mathrm{~h}$ UT is not clear.

The red dwarf CM Dra is the least massive eclipsing binary and it is older than classical flare stars; on the other hand, the orbital period of the system is unusually short. The interest on CM Dra is due to the fact that these propertics are linown to have opposite effects on the flare activity level (Vilhu et al., in press). CM Dra was monitored concurrently with IUE on July 5 , 1986. During the course of our optical monitoring the two partially averlapped flares shown in Figure 2 were detected.

Some characteristics of the observed flares are given in Table 1.

\section{REFERENCES}

Hartmann L., Bopp E.W., Dussault M., Noah F.V., Flimke A.: 1981, Astrophys. J. 249, tt2.

Viltu 0., et al.: 1988: submitted to Astron. Astrophys. 
Table 1.

$\begin{array}{llll}U T_{\text {max }} & t_{L} & t_{m} & F \quad \ldots m(U)\end{array}$

Giese 171.2A (4 Derentiol 1793)

$\begin{array}{llllll}1 & 165.1 & 0.4 & 1.0 & 0.5 & 0.7 \\ 2 & 165.4 .6 & 0.8 & 2.1 & 1.9 & 2.0 \\ 3 & 1824.0 & 1.5 & 1.5 & 0.1 & 0.5 \\ 4 & 18.30 .3 & 0.9 & 0.1 & 0.04 & 0.2 \\ 5 & 1912.0 & 1.4 & -.6 & 1.0 & 0.9\end{array}$

CM Dra (5 JuIy 1986)

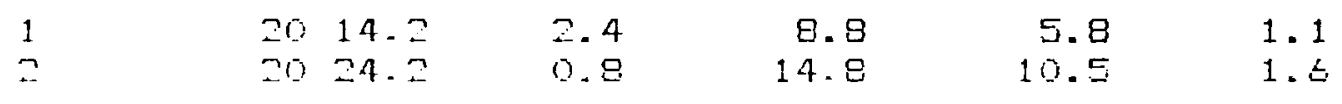

l_egenda

UTw-n : Lniversal Tine at flare maximuli.

$t_{1}, t_{-}$: Flare durations before ( $\left.T_{t}\right)$ and gfter ( $t_{-}$) maximun, in minutes.

F: Equivalent flare duration, in minutes.

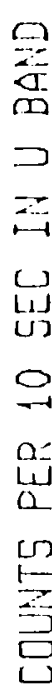

/BACKGRDUND IS SUBSTRACTED/

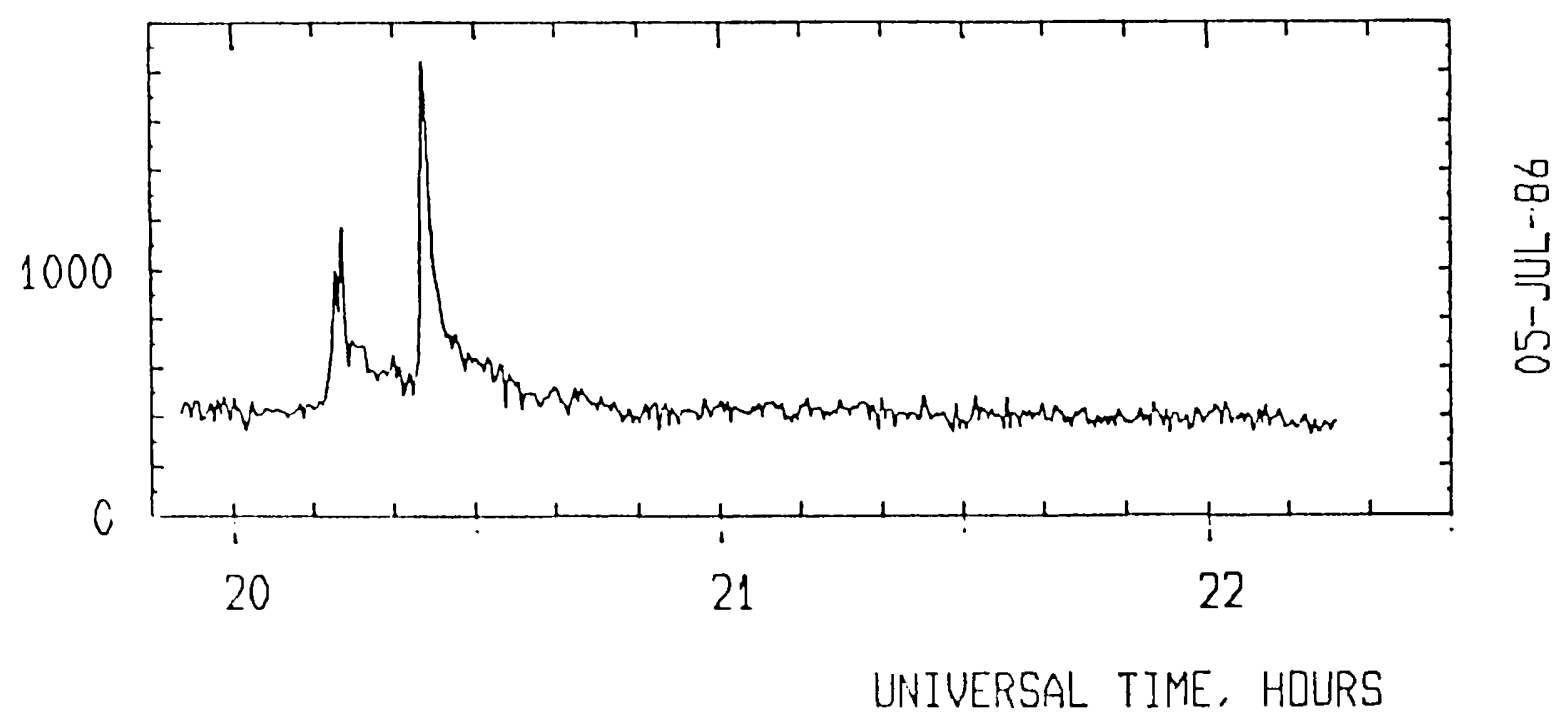

Figure 2. Fhotoelectric monitering of CM Drs 
/BACKGROUND IS SUBSTRACTED/

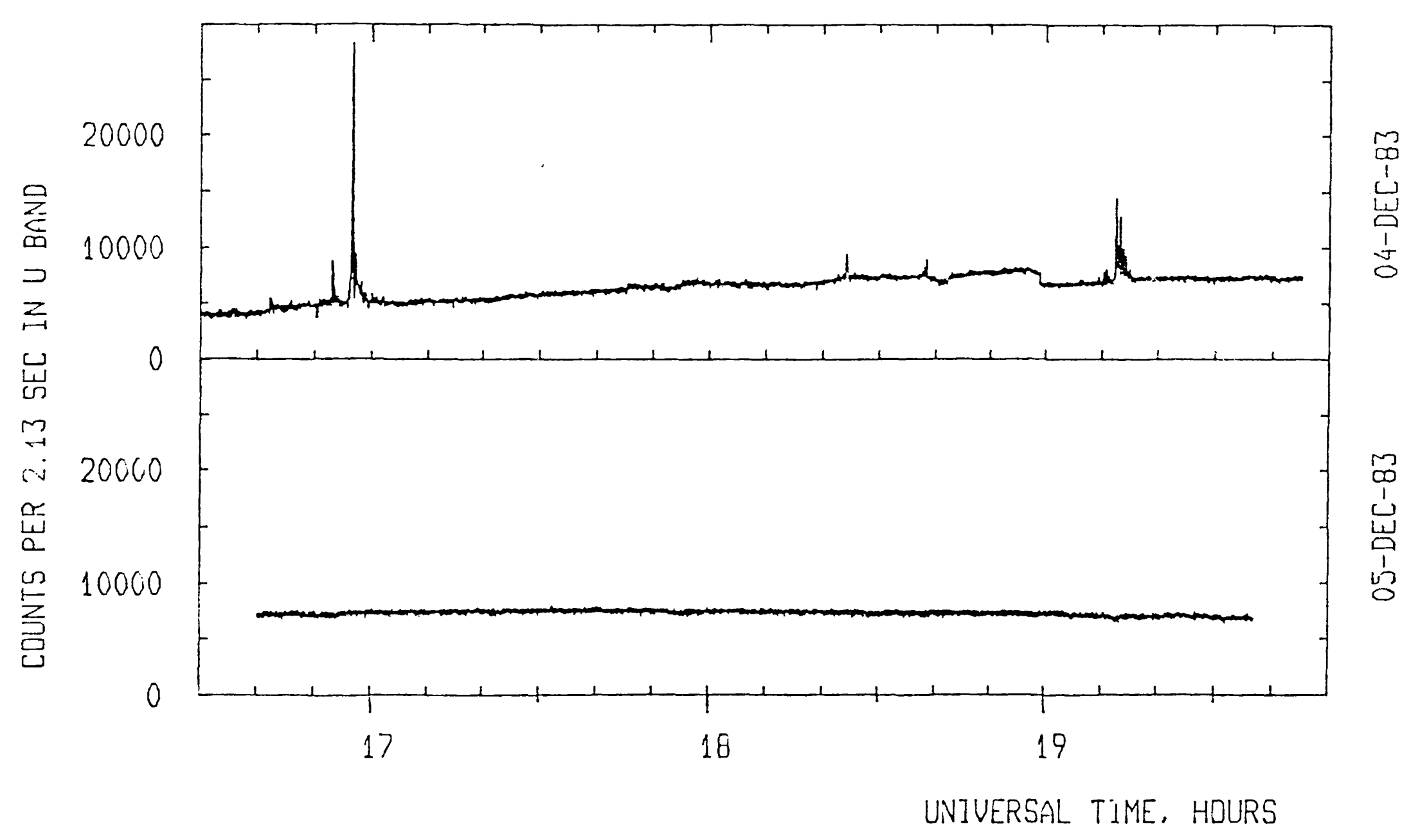

Figure 1. Photoelectric monitoring of Gliese 171.2A 